\title{
Prediction of the particle size and flow characteristics of powder blends for tableting by near-infrared spectroscopy and chemometrics
}

\author{
Rares IOVANOV ${ }^{1}$, Andreea Loredana VONICA ${ }^{2}$, Ioan TOMUTA ${ }^{1}$ \\ ${ }^{1}$ Department of Pharmaceutical Technology and Biopharmacy, Faculty of Pharmacy, "Iuliu Hatieganu" \\ University, Cluj-Napoca, Romania \\ 2 Preclinical Department, Faculty of Medicine, "Lucian Blaga" University, Sibiu, Romania
}

\begin{abstract}
The purpose of this research was to apply near-infrared (NIR) spectroscopy in combination with chemometrics to predict particle size and flow characteristics of a meloxicam powder blends for tableting. In order to develop calibration models for particle size (mean particle size, poly-dispersion index), and flow properties (angle of repose and time of flow) prediction, the NIR reflection spectra of different meloxicam powder blends prepared according to an experimental design were analyzed using different preprocessing methods by partial last-square (PLS) regression followed by leaveone-out cross-validation. Very good prediction ability was found for mean particle size, poly-dispersion index, angle of repose, and time of flow in models in whose development no preprocessing spectrum was applied. Also, a good prediction was found preprocessing spectrum such smoothing - moving average for particle size characteristics, and unit vector normalization for powder flow properties. Therefore, NIR-chemometric methods developed in this work can be useful for the prediction of the granulometric properties and parameters related to the flowability of the meloxicam powder blends and may be used as process analytical technology (PAT) tools for process control during meloxicam tablets manufacturing.
\end{abstract}

Keywords: near-infrared spectroscopy, chemometrics, PLS, particle size, powder flow, meloxicam

\section{INTRODUCTION}

In the manufacturing process of tablets powder characteristics as homogeneity and free flowing are essential to ensure uniformity of mass and drug content per dose unite. Both homogeneity and flowability are influenced by particle size and particle size distribution. In this context methods for easy assessing the particle size characteristics and the flowability properties of powder blends for tableting are of great importance for the pharmaceutical industry $[1,2]$.

NIR spectroscopy in combination with chemometrics allows rapid analysis of different characteristics of the intermediate or the finite product during the manufacturing of the tablets and it is an important 
toolbox in Process Analytical Technology (PAT). Direct analysis of intact solid dosage forms or pharmaceutical powder blends (as intermediate product) is considered to be an important goal for NIR analysis in the pharmaceutical industry, with the increasing needs for in-line, on-line, or at-line testing $[3,4,5]$.

Particle size characteristics (such are: mean particle size and poly-dispersion index) and flow characteristics (such are: time of flow and angle of repose) are well-known and important parameters of powders used in the pharmaceutical industry for manufacturing solid dosage forms $[6,7,8]$.

The NIR spectra of a solidus contain both chemical and physical information and have the potential to be used to measure one or multiple characteristics $[9,10,11]$. In the early applications of the near-infrared spectroscopy in pharmaceutical, they were focused on using different preprocessing methods to reduce or remove the physical interference, such as particle size or particle shape information, in order to improve the models' performance for chemical prediction $[3,12,13,14]$. Instead of reducing or removing the physical information from the NIR spectra, they can be extracted and can be used for the direct measurement of the particle size and flow characteristics of powder blends for tableting. A method is using chemometrics techniques to direct modeling the particle size characteristics or the flow properties with NIR spectra.

This research work aimed to develop a calibration model for predicting the particle size and flow properties of powder blends for tableting in order to be used for in-line or at-line monitoring the technological process of meloxicam tablet manufacturing.

\section{MATERIALS AND METHODS}

\section{Materials}

Meloxicam was provided by Uquifa, Spain; isomalt was provided by BENEO-Palatinit, Germany; microcrystalline cellulose and sodium starch glycolate was provided by JRS Pharma, Germany; and magnesium stearate was provided by UNDESA, Spain.

\section{Preparation of powder blends for NIR calibration}

The qualitative-quantitative formula of powder blends for meloxicam tablets preparation is presented in Table 1.
TABLE 1. The qualitative-quantitative formula of powder blends for meloxicam tablets preparation

\begin{tabular}{|c|r|c|}
\hline & $\mathrm{mg} /$ tablet & $\%$ \\
\hline Meloxicam & 15.00 & 6.25 \\
\hline Isomalt & 111.80 & 46.58 \\
\hline $\begin{array}{c}\text { Microcrystalline } \\
\text { Cellulose PH 102 }\end{array}$ & 100 & 41.67 \\
\hline $\begin{array}{c}\text { Sodium starch } \\
\text { glycolate }\end{array}$ & 12 & 5.00 \\
\hline $\begin{array}{c}\text { Magnesium } \\
\text { stearate }\end{array}$ & 1.2 & 0.50 \\
\hline & $\mathbf{2 4 0 . 0 0}$ & \\
\hline
\end{tabular}

Powder mixing: meloxicam, microcrystalline cellulose, isomalt, and sodium starch glycolate were mixed for 5 minutes in a planetary mixer (Erweka, Germany). Additionally, magnesium stearate was added, and the final powder blends were mixed for more than one minute.

Subsequently, the powder blends were sieved into three different particle size classes (Table 2). Then, using these different particle size classes samples with known composition were prepared in order to build a calibration model, according to the ratio from the DoE matrix (Table 4).

\section{TABLE 2. Granulometric classes}

\begin{tabular}{|c|c|}
\hline Particle size classes & Size interval \\
\hline Fraction 1 & $0-100$ \\
\hline Fraction 2 & $100-200$ \\
\hline Fraction 3 & $200-300$ \\
\hline
\end{tabular}

TABLE 3. Design of experimental variables. Independent variables and levels of variation - input variables

\begin{tabular}{|l|c|c|c|c|}
\hline & & $\mathbf{- 1}$ & $\mathbf{0}$ & $\mathbf{+ 1}$ \\
\hline Fraction 1 & $\mathrm{X}_{1}$ & 1 & 2 & 3 \\
\hline Fraction 2 & $\mathrm{X}_{2}$ & 1 & 2 & 3 \\
\hline Fraction 3 & $\mathrm{X}_{3}$ & 1 & 2 & 3 \\
\hline
\end{tabular}

Dependent variables - output variables

\begin{tabular}{|r|c|}
\hline Mean particle size & Y1 \\
\hline Poly-dispersion index & Y2 \\
\hline Angle of repose & Y3 \\
\hline Time of flow & Y4 \\
\hline
\end{tabular}

For the powder characteristics calibration, synthetic powder blends with known properties were prepared according to a design of experiment (DoE) with three factors and two levels. The input variables of the DoE 
were the granulometric classes and the levels were the mixing ratios. The output variables of the DoE were granulometric characteristics of the powder (particle size and poly-dispersion index) and flow properties (angle of response and time of flow) (Table 3). The matrix of the DoE is shown in Table 4.

TABLE 4. The matrix of the design of experiments (DOE)

\begin{tabular}{|c|c|c|c|c|}
\hline $\begin{array}{c}\text { Exp } \\
\text { Name }\end{array}$ & Run Order & $\mathbf{x}_{\mathbf{1}}$ & $\mathbf{x}_{\mathbf{2}}$ & $\mathbf{x}_{\mathbf{3}}$ \\
\hline N1 & 1 & 1 & 1 & 1 \\
\hline N2 & 6 & 3 & 1 & 1 \\
\hline N3 & 8 & 1 & 3 & 1 \\
\hline N4 & 7 & 3 & 3 & 1 \\
\hline N5 & 4 & 1 & 1 & 3 \\
\hline N6 & 9 & 3 & 1 & 3 \\
\hline N7 & 5 & 1 & 3 & 3 \\
\hline N8 & 10 & 3 & 3 & 3 \\
\hline N9 & 3 & 2 & 2 & 2 \\
\hline N10 & 2 & 2 & 2 & 2 \\
\hline
\end{tabular}

$X_{1}$ - Fraction 0-100; $X_{2}$ - Fraction 100-200; $X_{3}$ - Fraction 200-300.

\section{NIR spectroscopic analysis}

NIR spectra of powder blends were registered using a NIR spectrometer (Antaris II FT-NIR Analyzer from TermoElectron, SUA). The spectra were recorded using an indium gallium arsenide (InGaAs) detector in reflectance sampling configuration, equipped with a system for sample rotation during the measurements in order to obtain representative spectra. Each reflectance spectrum was recorded by integrating 32 scans taken from 11,000 to $4,000 \mathrm{~cm}-1$ at $8 \mathrm{~cm}-1$ resolution.

\section{Data processing}

In order to construct the calibration methods, different spectra preprocessing methods were used to enhance the information of interest for the study and to decrease the influence of the side information contained in the spectra. The spectra preprocessing methods were smoothing, first derivative (FD). second derivative (SD), standard normal variate (SNV), unit vector normalization (UNV) [11]. The ability and the efficiency of tested calibration models were evaluated using the Root Mean Square Error of Cross Validation (RMSECV) using the following formula:

$$
\begin{aligned}
& \text { RMSECV }=\sqrt{\frac{\text { PRESS }}{n}} \\
& \text { PRESS }=\sum\left(Y_{\text {pred }}-Y_{\text {true }}\right)^{2}
\end{aligned}
$$

where, $Y_{\text {true }}=$ true properties

$Y_{\text {pred }}=$ predicted properties

$n=$ number of training samples

\section{Software}

Unscrambler software package from Camo X, Norway, was used to perform Partial Least Squares (PLS) regression. The calibration set (Table 4), which consists of the component mixtures in a suitable combination, was prepared according to a design of experiments built using the Modde software. Camo software allows validation of the models by full cross-validation, a procedure that consists of an iterative calibration by removing, in turn, each spectrum from the training set and then predicting the excluded sample with that calibration $[2,9,14]$.

\section{Particle size characteristics of powder blends}

The powder blends were sieved using AS Basic sieve shaker (Retsch, Germany) equipped with a set of 4 sieves $(100,200,300,400 \mu \mathrm{m})$. The mean particle size and poly-dispersion index of powder blends were determined according to a well-known method [15].

\section{Flow properties of the powder blends}

The angle of repose and the time of flow were determined according to the European Pharmacopeia methods [16].

\section{RESULTS AND DISCUSSION}

\section{Particle size and flow characteristics of the synthetic powder blends}

In order to develop a calibration model for the particle size and the flow characteristics prediction, ten synthetic powder blends according to the experimental design matrix (table 4) were prepared. The results of particle size and flow characteristics of the prepared synthetic powder blends are presented in Table 5.

TABLE 5. The particle size and the flow characteristics of calibration samples

\begin{tabular}{|c|c|c|c|c|}
\hline $\begin{array}{c}\text { Exp } \\
\text { Name }\end{array}$ & $\mathbf{Y}_{\mathbf{1}}$ & $\mathbf{Y}_{\mathbf{2}}$ & $\mathbf{Y}_{\mathbf{3}}$ & $\mathbf{Y}_{\mathbf{4}}$ \\
\hline N1 & 150.0 & 54.71 & 12.03 & 91.2 \\
\hline N2 & 110.0 & 73.09 & 13.47 & 106.0 \\
\hline N3 & 150.0 & 42.38 & 11.63 & 85.5 \\
\hline N4 & 121.4 & 57.9 & 12.53 & 102.0 \\
\hline N5 & 190.0 & 42.3 & 9.17 & 74.7 \\
\hline N6 & 75.0 & 58.0 & 12.63 & 105.8 \\
\hline N7 & 150.0 & 42.0 & 11.45 & 80.9 \\
\hline N8 & 178.6 & 39.4 & 11.10 & 92.7 \\
\hline N9 & 150.0 & 54.7 & 12.00 & 88 \\
\hline N10 & 150.0 & 54.7 & 12.10 & 93.1 \\
\hline
\end{tabular}

Y1 - mean particle size; Y2 - poly-dispersion index; Y3 - angle of repose; $\mathrm{Y} 4$ - time of flow 

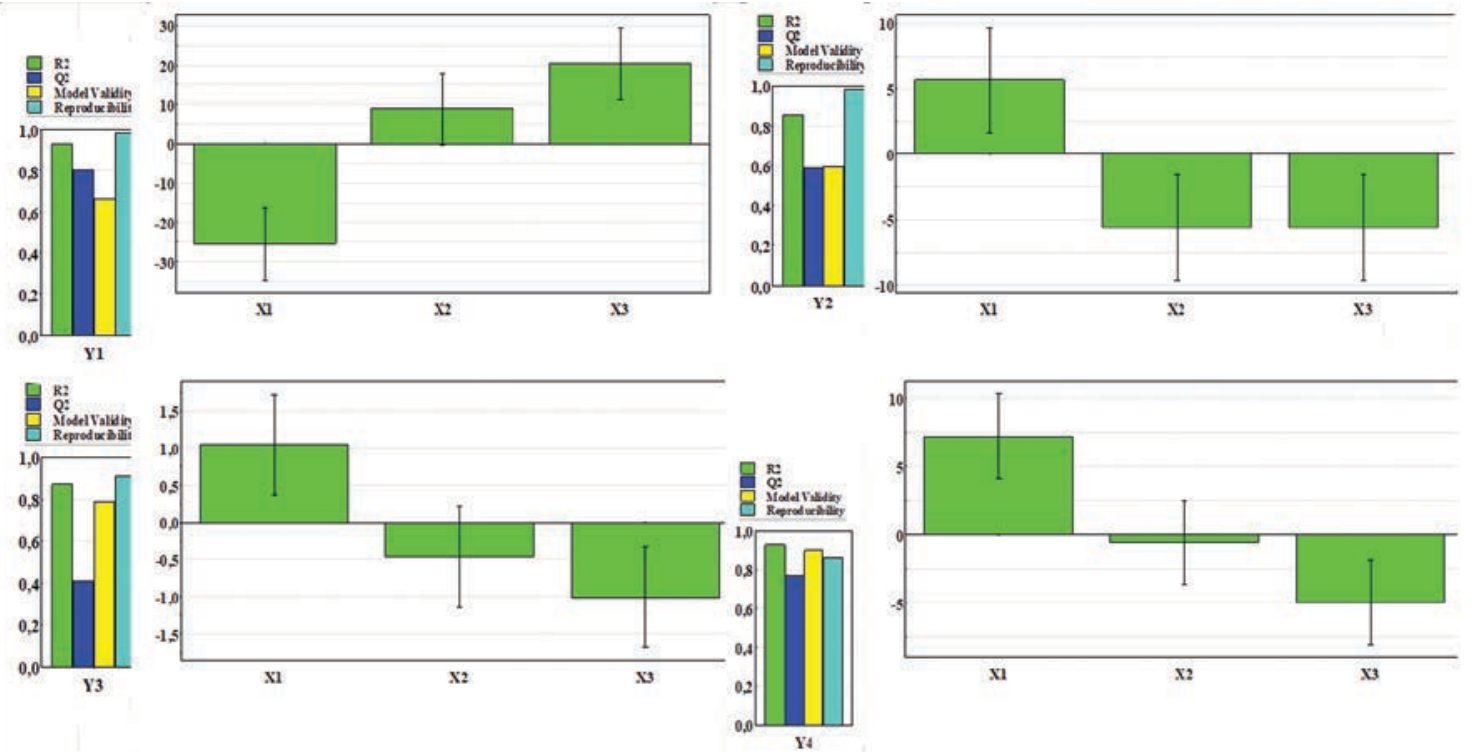

FIGURE 1. Influence of fractions used to obtain synthetic powder mixture on its particle size and flow characteristics. Y1 - Mean particle size; Y2 - Poly-dispersion index; Y3 - Angle of repose, Y4 - Time of flow; X1 - Fraction 0-100; X2 - Fraction 100-200; X3-Fraction 200-300

Modde software was used to find correlations between fractions used to obtain synthetic powder blends and particle size and flow characteristics of obtained powder blends. The results are shown in figure 1 .

According to obtained results (Figure 1 ) a very good correlation was found between the fraction used in the preparation of the synthetic mixtures and particle size and flow characteristics, respectively. A high amount of fraction 0-100 leads to obtaining synthetic powder blends with a small mean diameter, large poly-dispersion index, and low flow properties. On the other hand, a large amount of fraction 200-300 conducts to obtaining a synthetic powder blend with high mean diameter, small poly-dispersion index, and good flow properties (small angle of repose and small time of flow).

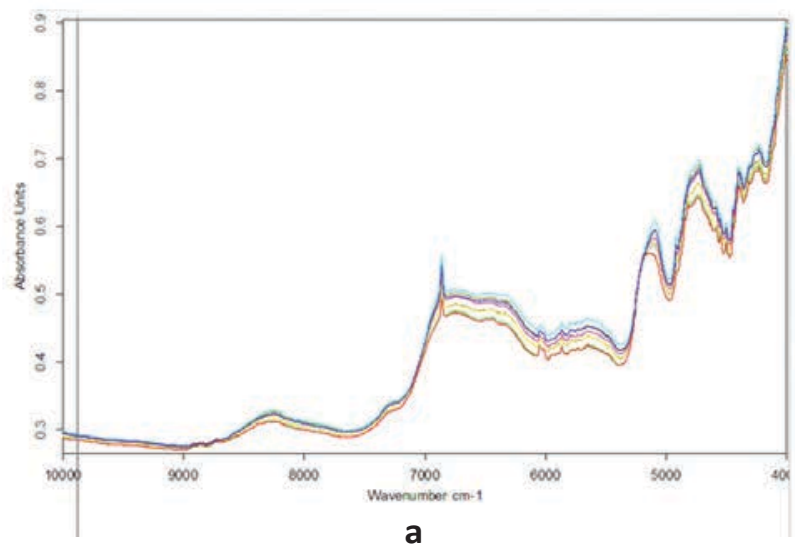

\section{Spectra investigation}

The development of a calibration model is an iterative activity that consists of checking different spectral preprocessing methods, as well as their combination with different spectral regions. Both the whole spectral range and specific spectral regions containing strong bands and different spectral preprocessing were evaluated in order to find good calibration models. The NIR spectra of the calibration powder blends are shown in figure $2 a$. In figure $2 b$ is shown the spectra of the three fractions used in the calibration model. As shown in figure 2.b. significant differences are present especially in the range 7,000$4,000 \mathrm{~cm}-1$ of the spectrums. This region was used for model calibration.

FIGURE 2. NIR reflectance spectra of the ten calibration powder blends (a) and the three fractions used in the preparation of the calibration model according to the experimental design (b) 


\section{Multivariate calibration for particle size characteristics}

Different multivariate calibration models were applied to find a direct correlation between the NIR spectra of ten calibration powder blends and their particle size characteristics. Cross-validation has been used to select the optimum calibration model $[17,18]$. The tested models were evaluated regarding the predictive abilities by plotting the actual known properties against the predicted properties and calculation the correlation coefficient (R). Also, as a diagnostic test for examining the errors in the predicted characteristics of the tested models, the RMSECV was used. The RMSECV indicates both the precision and the accuracy of the predictions. The correlation coefficients (R2) and the RMSECV obtained on the synthetic powder blends from the calibration matrix of theirs NIR reflection spectra using the PLS calibration models for prediction of the particle size are shown in Table 6.

TABLE 6. Statistical parameter for particle size calibration

\begin{tabular}{|c|c|c|c|c|}
\hline Method & & RMSECV & $\mathbf{R}^{2}$ & $\begin{array}{l}\text { No. } \\
\text { Factors }\end{array}$ \\
\hline \multirow{2}{*}{ None } & Calibration & 3.4297 & 0.97158 & 2 \\
\hline & Validation & 5.4112 & 0.92663 & 2 \\
\hline \multirow{2}{*}{$\begin{array}{l}\text { Smoothing } \\
\text { - moving } \\
\text { average }\end{array}$} & Calibration & 3.4297 & 0.94159 & 2 \\
\hline & Validation & 5.4106 & 0.88868 & 2 \\
\hline \multirow{2}{*}{$\begin{array}{l}\text { Smoothing - } \\
\text { Savitsky Golay }\end{array}$} & Calibration & 0.0012 & 0.97765 & 3 \\
\hline & Validation & 0.0037 & 0.80429 & 3 \\
\hline \multirow{2}{*}{$\begin{array}{l}\text { Unit vector } \\
\text { normalization }\end{array}$} & Calibration & 4.0686 & 0.91778 & 3 \\
\hline & Validation & 9.8429 & 0.63162 & 3 \\
\hline \multirow{2}{*}{$\begin{array}{c}\text { Standard } \\
\text { normal } \\
\text { variable }\end{array}$} & Calibration & 4.0429 & 0.91882 & 3 \\
\hline & Validation & 9.5718 & 0.66163 & 3 \\
\hline \multirow{2}{*}{$\begin{array}{l}\text { Noris Grap } \\
\text { first derivate }\end{array}$} & Calibration & 0.9182 & 0.99581 & 4 \\
\hline & Validation & 7.6618 & 0.77679 & 4 \\
\hline \multirow{2}{*}{$\begin{array}{l}\text { Noris Grap } \\
\text { second } \\
\text { derivate }\end{array}$} & Calibration & 0.7699 & 0.99705 & 4 \\
\hline & Validation & 11.3777 & 0.50777 & 4 \\
\hline
\end{tabular}

The model was selected based on the following criteria: the smallest number of factors (principal components), it has the smallest RMSECV value, the highest R2 value, and the RMSECV value for that model is not significantly greater than RMSECV for the model with one or more additional factors. The RMSECV values plotted as a function of PLS factors obtained using different spectral preprocessing methods for prediction the particle size are shown in Figure 3.

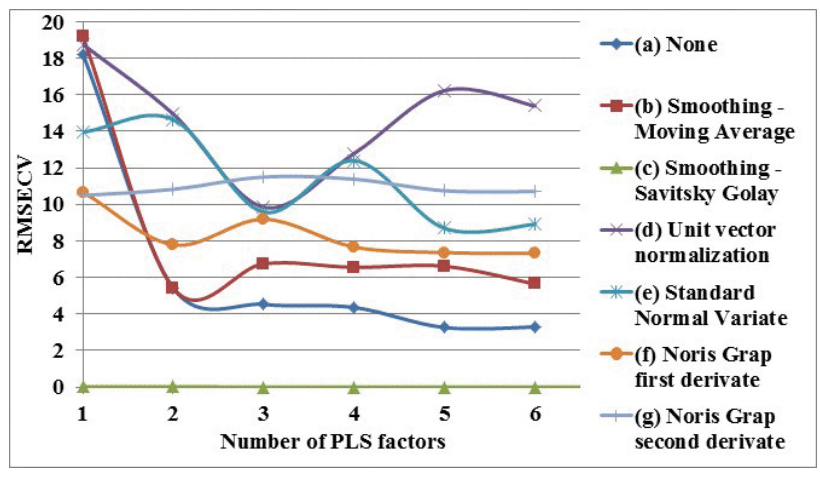

FIGURE 3. Plotting the RMSECV function of the PLS factors for particle size characteristics prediction

According to the RMSECV decrease and its correlation coefficient, two PLS factors were found to be optimum for using PLS methods without any pretreatment and smoothing - moving average pretreatment.

\section{Results of control samples for particle size characteristics}

In order to evaluate the prediction ability of the NIR chemometrics methods, six control samples were analyzed using the chemometric methods found above and the reference sieves method. Tables 7 and 8 have listed the results for the predictive ability and those obtained by sieves analysis on the six control samples regarding particle size characteristics (mean particle size and in for poly-dispersion index).

The data arrays of the control samples obtained using the reference sieves method and by applying the chemometric methods were compared. No statistically significant difference (P-type 1 error $>0.5$ ) was found between the means obtained for the three arrays of predictive and reference data, considering a confidence level of $95 \%$. Therefore, a good similarity can be considered between the obtained results using the sieves reference method and the proposed NIR chemometric methods and prove the performance of the NIR chemometric methods.

\section{Multivariate calibration for powder flow}

The correlation coefficients (R2) and the RMSECV obtained on the synthetic powder blends from the calibration matrix of theirs NIR reflection spectra using the PLS calibration models for prediction of the angle of repose are shown in Table 9. The RMSECV values plotted as a function of PLS factors obtained using different spectral preprocessing methods for predicting the angle of repose are shown in Figure 4. 
ORIGINAL RESEARCH PAPERS

TABLE 7. Obtained results for mean particle size on control samples using NIR-chemometric methods and reference sieves method

\begin{tabular}{|c|c|c|c|c|c|c|c|}
\hline \multirow{3}{*}{ Control samples } & \multirow[b]{2}{*}{ Taken } & \multicolumn{2}{|c|}{ NT - PLS } & \multicolumn{2}{|c|}{$\begin{array}{l}\text { Smoothing - moving } \\
\text { average - PLS }\end{array}$} & \multicolumn{2}{|c|}{ Sieve analysis - reference } \\
\hline & & Found & Recovery & Found & Recovery & Found & Recovery \\
\hline & $(\mu \mathrm{m})$ & $(\mu \mathrm{m})$ & (\%) & $(\mu \mathrm{m})$ & (\%) & $(\mu \mathrm{m})$ & (\%) \\
\hline P1 & 150 & 148 & 98.42 & 147 & 98.45 & 145 & 96.67 \\
\hline P2 & 125 & 130 & 104.35 & 130 & 104.39 & 124 & 99.20 \\
\hline P3 & 150 & 151 & 100.78 & 151 & 100.80 & 144 & 96.00 \\
\hline P4 & 131 & 142 & 108.11 & 142 & 108.14 & 135 & 102.72 \\
\hline P5 & 190 & 193 & 101.55 & 192 & 101.56 & 186 & 97.89 \\
\hline P6 & 95 & 100 & 105.47 & 120 & 126.58 & 103 & 108.42 \\
\hline Mean & 140.24 & 144.08 & & 147.45 & & 139.50 & \\
\hline SD & 31.70 & 30.22 & & 25.07 & & 27.59 & \\
\hline$t_{\text {exp }}$ & & 0.2123 & & 0.4144 & & 0.0388 & \\
\hline $\mathrm{P}$ (type 1 error) & & 0,8349 & & 0.6865 & & 0,9697 & \\
\hline
\end{tabular}

TABLE 8. Obtained results for poly-dispersion index on control samples using NIR-chemometric methods and reference sieves method

\begin{tabular}{|c|c|c|c|c|c|c|c|}
\hline \multirow{3}{*}{ Control samples } & \multirow[b]{2}{*}{ Taken } & \multicolumn{2}{|c|}{ NT - PLS } & \multicolumn{2}{|c|}{$\begin{array}{l}\text { Smoothing - moving } \\
\text { average - PLS }\end{array}$} & \multicolumn{2}{|c|}{ Sieve analysis - reference } \\
\hline & & Found & Recovery & Found & Recovery & Found & Recovery \\
\hline & $(\mu \mathrm{m})$ & $(\mu \mathrm{m})$ & (\%) & $(\mu \mathrm{m})$ & (\%) & $(\mu \mathrm{m})$ & (\%) \\
\hline P1 & 55 & 56 & 101.68 & 55 & 101.65 & 58 & 106.02 \\
\hline P2 & 67 & 62 & 92.10 & 61 & 92.08 & 66 & 98.51 \\
\hline P3 & 49 & 54 & 110.70 & 54 & 110.68 & 53 & 108.16 \\
\hline P4 & 58 & 58 & 99.63 & 57 & 99.61 & 56 & 96.68 \\
\hline P5 & 37 & 35 & 94.83 & 35 & 94.79 & 33 & 89.19 \\
\hline P6 & 58 & 65 & 111.40 & 64 & 111.38 & 63 & 108.57 \\
\hline Mean & 53.94 & 54.84 & & 54.82 & & 54.83 & \\
\hline SD & 10.15 & 10.42 & & 10.42 & & 11.69 & \\
\hline $\mathrm{t}_{\text {exp }}$ & & 0.1669 & & 0.0567 & & 0.1318 & \\
\hline P (type 1 error) & & 0,8707 & & 0.9558 & & 0,8977 & \\
\hline
\end{tabular}


TABLE 9. Statistical parameter for the angle of repose

\begin{tabular}{|c|l|c|c|c|}
\hline Method & & RMSECV & $\mathbf{R}^{\mathbf{2}}$ & $\begin{array}{c}\text { No. } \\
\text { Factors }\end{array}$ \\
\hline \multirow{2}{*}{ None } & Calibration & $\mathbf{2 . 7 5 4 3}$ & $\mathbf{0 . 9 5 7 5}$ & $\mathbf{6}$ \\
\cline { 2 - 5 } & Validation & $\mathbf{3 . 8 2 7 9}$ & $\mathbf{0 . 9 3 0 7}$ & $\mathbf{6}$ \\
\hline $\begin{array}{c}\text { Smoothing } \\
\text { - Moving } \\
\text { Average }\end{array}$ & Calibration & 2.7652 & 0.9471 & 6 \\
\cline { 2 - 5 } & Validation & 4.2177 & 0.8955 & 6 \\
\hline $\begin{array}{c}\text { Smoothing - } \\
\text { Savitsky Golay }\end{array}$ & Calibration & 2.7651 & 0.9471 & 6 \\
\cline { 2 - 5 } $\begin{array}{c}\text { Unit vector } \\
\text { normalization }\end{array}$ & Calidation & 4.1957 & 0.8832 & 6 \\
\cline { 2 - 5 } & Validation & $\mathbf{3 . 4 4 1 6}$ & $\mathbf{0 . 9 3 7 9}$ & $\mathbf{5}$ \\
\hline $\begin{array}{c}\text { Standard } \\
\text { Normal } \\
\text { Variable }\end{array}$ & Calibration & 2.7263 & 0.9486 & 4 \\
\cline { 2 - 5 } & Validation & 3.1604 & 0.9296 & 4 \\
\hline $\begin{array}{c}\text { Noris Grap } \\
\text { first derivate }\end{array}$ & Calibration & 2.7215 & 0.9487 & 5 \\
\cline { 2 - 5 } & Validation & 3.2321 & 0.9117 & 5 \\
\hline \multirow{2}{*}{$\begin{array}{c}\text { Noris Grap } \\
\text { second } \\
\text { derivate }\end{array}$} & Calibration & 1.3454 & 0.9874 & 5 \\
\cline { 2 - 5 } & Validation & 3.5266 & 0.9087 & 5 \\
\hline
\end{tabular}

According to the RMSECV decrease and its correlation coefficient, for the prediction of the angle of repose was found to be optimum 6 PLS factors when using PLS methods without any pretreatment and 5 PLS factors when using PLS methods with Unit Vector Normalization pretreatment.

The correlation coefficients (R2) and the RMSECV obtained on the synthetic powder blends from the calibration matrix of theirs NIR reflection spectra using the PLS calibration models for prediction of the time of flow are shown in Table 10. The RMSECV values plotted as a function of PLS factors obtained using different spectral preprocessing methods for predicting the time of flow are shown in Figure 5.

According to the RMSECV decrease and its correlation coefficient, for the prediction of the time of flow were found to be optimum 2 PLS factors when using PLS methods without any pretreatment and 2 PLS factors when using PLS methods with Unit Vector Normalization pretreatment.

\section{Results of control samples for powder flow characteristics}

In order to evaluate the prediction ability regarding the powder flow characteristics of the NIR chemometrics methods, six control samples were analyzed using the chemometric methods found above and European Pharmacopeia reference methods. Table 11 has listed the results for the

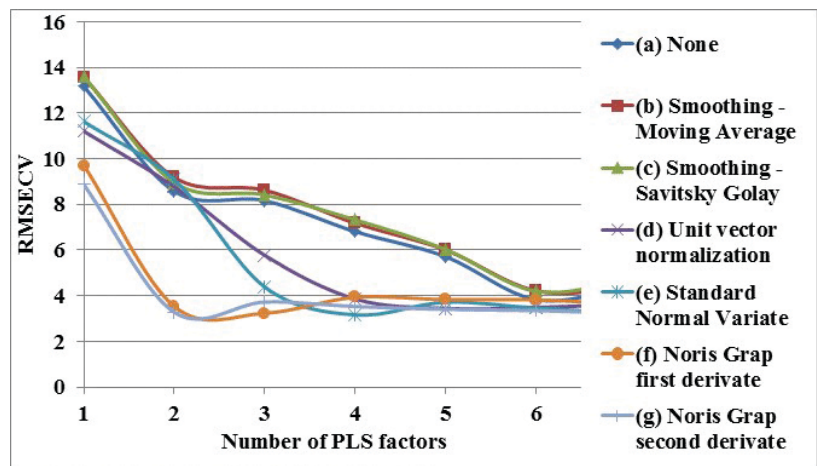

FIGURE 4. Plotting the RMSECV function of the PLS factors for the angle of repose

TABLE 10. Statistical parameter for the time of flow

\begin{tabular}{|c|c|c|c|c|}
\hline Method & & RMSECV & $\mathbf{R}^{2}$ & $\begin{array}{c}\text { No. } \\
\text { Factors }\end{array}$ \\
\hline \multirow{2}{*}{ None } & Calibration & 8.2681 & 0.9451 & 2 \\
\hline & Validation & 9.4518 & 0.9129 & 2 \\
\hline \multirow{2}{*}{$\begin{array}{l}\text { Smoothing } \\
\text { - Moving } \\
\text { Average }\end{array}$} & Calibration & 8.2790 & 0.9148 & 2 \\
\hline & Validation & 9.5766 & 0.8976 & 2 \\
\hline \multirow{2}{*}{$\begin{array}{l}\text { Smoothing - } \\
\text { Savitsky Golay }\end{array}$} & Calibration & 8.2782 & 0.9148 & 2 \\
\hline & Validation & 9.7879 & 0.8937 & 2 \\
\hline \multirow{2}{*}{$\begin{array}{l}\text { Unit vector } \\
\text { normalization }\end{array}$} & Calibration & 8.0666 & 0.9191 & 2 \\
\hline & Validation & 9.6286 & 0.8925 & 2 \\
\hline \multirow{2}{*}{$\begin{array}{c}\text { Standard } \\
\text { Normal } \\
\text { Variable }\end{array}$} & Calibration & 8.7187 & 0.9055 & 2 \\
\hline & Validation & 9.9839 & 0.8775 & 2 \\
\hline \multirow{2}{*}{$\begin{array}{l}\text { Noris Grap } \\
\text { first derivate }\end{array}$} & Calibration & 3.2241 & 0.9870 & 6 \\
\hline & Validation & 10.5369 & 0.8708 & 6 \\
\hline \multirow{2}{*}{$\begin{array}{l}\text { Noris Grap } \\
\text { second } \\
\text { derivate }\end{array}$} & Calibration & 1.0848 & 0.9485 & 6 \\
\hline & Validation & 10.7488 & 0.9069 & 6 \\
\hline
\end{tabular}

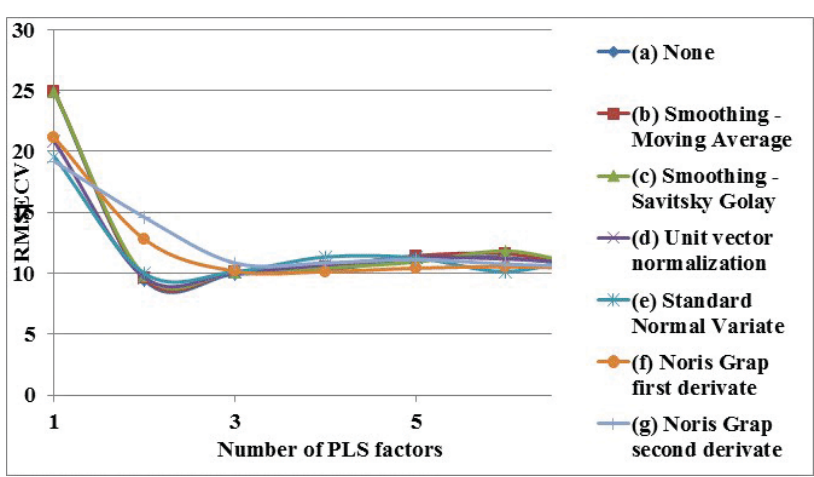

FIGURE 5. Plotting the RMSECV function of the PLS factors for the time of flow

predictive ability and those obtained by European Pharmacopeia methods on the six control samples regarding flow characteristics (the angle of response and the time of flow). 
TABLE 11. Obtained results for the angle of response and the time of flow on control samples using NIR-chemometric methods and European Pharmacopeia reference methods

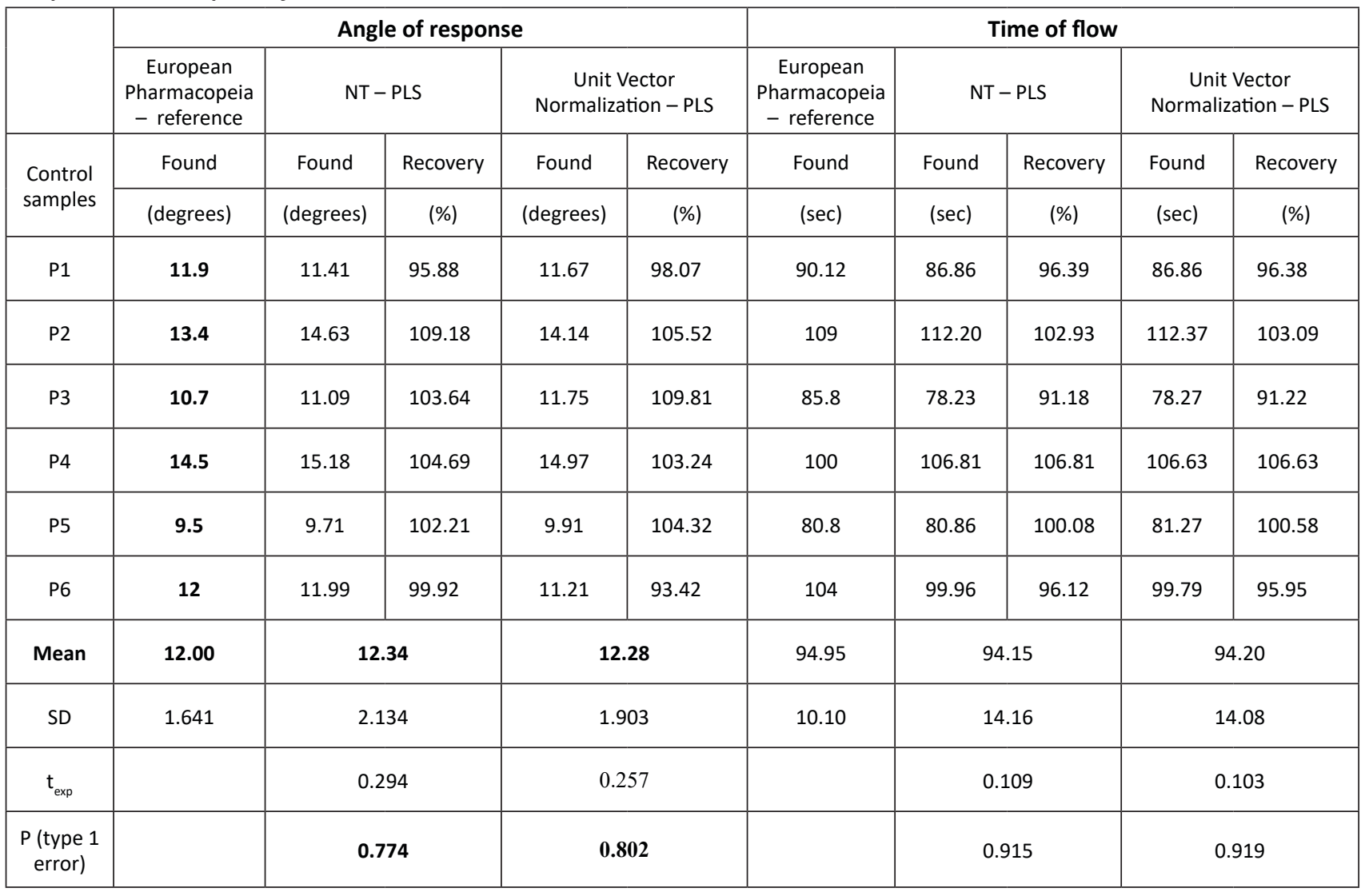

The data arrays of the control samples obtained using the European Pharmacopeia reference methods and by applying the chemometric methods were compared. No statistically significant difference (P-type 1 error $>0.5$ ) was found between the means obtained for the three arrays of predictive and reference data, considering a confidence level of $95 \%$. Therefore, a good similarity can be considered between the obtained results using the European Pharmacopeia reference methods and the proposed NIR chemometric methods and prove the performance of the NIR chemometric methods regarding determination the flow characteristics of powder blend for tableting (the angle of response and the time of flow).

Similar results were obtained by Porfire et all on indapamide powder blends for tableting [7].

Therefore, the developed NIR methods can predict the pharmaceutical properties of powder blends very useful during the tableting process, as are particle size and flowability, and can be exploited as PAT tools.

\section{CONCLUSIONS}

NIR spectroscopy in combination with chemometrics was evaluated to direct assay the physical characteristics of meloxicam powder blends for tableting of interest for pharmaceutical processing as particle size and flowability. Different PLS calibration models were developed and evaluated regarding the prediction of the mean particle size, the poly-dispersion index, the angle of repose, and the time of flow.

The results show a very good prediction ability of those parameters and allow to be determinate directly from NIR reflection spectra of powder blends for tableting, without any sample preparation. Such quick NIR - chemometric methods can be used for on-line, in-line, or at-line monitoring of the meloxicam tablets manufacturing process and are helpful in achieving the goals of the process analytical technology (PAT). 


\section{REFERENCES}

1. Allen LV, Ansel HC. Ansel's pharmaceutical dosage forms and drug delivery systems. 10th Edition. Baltimore: Lippincott Williams \& Wilkins Inc., 2014.

2. Tovey GD. Pharmaceutical Formulation: The Science and Technology of Dosage Forms. Croydon: Royal Society of Chemistry Inc., 2018.

3. Bakeev K.A. Process Analytical Technology. Spectroscopic Tools and Implementation Strategies for the Chemical and Pharmaceutical Industries, 2nd Edition. New-York: Wily Inc, 2010.

4. Yu LX. Pharmaceutical quality by design: product and process development, understanding, and control. Pharm Res. 2008;25(4):781-91.

5. Blanco M, Peguero A. Analysis of Pharmaceuticals by NIR spectroscopy without a reference method. TrAC - Trends in Analytical Chemistry. 2010;29(10):1127-1136.

6. Rus LL, Casian T, lovanov RI, Orzea RM, Onișor I, Muntean AC, Tomuță I. Quantitative characterization of sustained release tablets with diclofenac sodium by means of near-infrared spectroscopy and chemometry. Farmacia. 2020;68(4):728-739.

7. Porfire A, Rus L, Vonica AL, Tomuta I.. High-throughput NIRchemometric methods for determination of drug content and pharmaceutical properties of indapamide powder blends for tabletting, J Pharm Biomed Anal. 2012;70:301-309.

8. Liew CV, Karande AD, Heng PWS. In-line quantification of drug and excipients in cohesive powder blends by near infrared spectroscopy. Int J Pharm. 2010;386(1-2):138-148.

9. Roggo Y, Chalus P, Maurer L, Lema-Martinez C, Edmond A, Jent N. A review of near infrared spectroscopy and chemometrics in pharmaceutical technologies. J Pharm Biomed Anal. 2007;44(3):683-700.
10. Blanco M, Peguero A. Influence of physical factors on the accuracy of calibration models for NIR spectroscopy. J Pharm Biomed Anal. 2010;52(1):59-65.

11. Gavan A, lurian S, Casian T, Porfire A, Porav S, Voina I, Oprea A, Tomuta I. Fluidised bed granulation of two APIs: QbD approach and development of a NIR in-line monitoring method. Asian J Pharm Sci. 2020;15(4):506-517.

12. Otsuka M, Mouri Y, Matsuda Y. Chemometric evaluation of pharmaceutical properties of antipyrine granules by near-infrared spectroscopy. AAPS PharmSciTech. 2003;4(3):E47.

13. Alcalà $\mathrm{M}$, Blanco M, Bautista $\mathrm{M}$, González JM. On-line monitoring of a granulation process by NIR spectroscopy. J Pharm Sci. 2010;99(1):336-45.

14. Xiaobo Z, Jiewen Z, Povey MJ, Holmes M, Hanpin M. Variables selection methods in near-infrared spectroscopy. Anal Chim Acta. 2010;667(1-2):14-32.

15. Tomuţă I, Porfire A, Achim M, lurian S, Hales D, Tefas L, Casian T, lovanov R. Industrial pharmaceutical technology. Pharmaceutical development of generic drugs. Cluj-Napoca: Risoprint Inc, 2020.

16. European Pharmacopeia (2.9.16. Flowability, 2.9.36. Powder flow), 10th Edition, 2020.

17. Eriksson L, Johansson E, Kettaneh-Wold N, Trygg J, Wikström C, Wold S. Multi- and Megavariate Data Analysis Part I, Basic Principles and Applications, Second revised and enlarged edition, Umea: Umetrics Academy Inc., 2006.

18. Esbensen KH. Multivariate Data Analysis - in practice. 5th Edition. CAMO Software, Oslo, 2010. 